\title{
Capacidade estatal e dívida pública no Brasil: O Caso da Secretaria do Tesouro Nacional
}

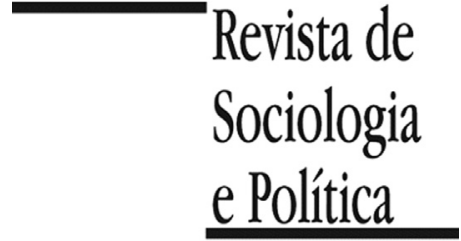

DOI 10.1590/1678-987320287502

\author{
Maria Rita Loureiro' (iD, Felipe Calabrez" \\ 'Departamento de Gestão Pública, Escola de Administração de Empresas de São Paulo, São Paulo, SP, Brasil. \\ ${ }^{\mathrm{II}}$ Curso de Relações Internacionais, Faculdades Metropolitanas Unidas, São Paulo, SP, Brasil.
}

\begin{abstract}
RESUMO Introdução: A literatura sobre capacidade estatal tem crescido nas últimas décadas, mas vários problemas teóricos e metodológicos têm sido apontados nos estudos sobre o tema. Mesmo tendo caráter mais prático e orientado por preocupações de policymakers, o conceito de capacidade estatal pode ter também utilidade analítica. Assim, este artigo o retoma e o redefine para explicar processos de transformações dentro do Estado brasileiro. Materiais e Métodos: Realizamos aqui um estudo de caso do processo de construção de capacidade na área fiscal por parte do Estado no Brasil. O objeto empírico de análise é a Secretaria do Tesouro Nacional do Ministério da Fazenda, órgão criado em contexto de crise fiscal do Estado, encarregado da gestão do endividamento público e do controle unificado da execução orçamentária do governo federal. O material empírico da análise é composto de elementos qualitativos e quantitativos. Resultados: Em diálogo com a literatura e distinguindo capacidade de resultado, a análise mostra que a despeito de variações temporais apresentadas pela área fiscal (maior ou menor déficit, maior ou menor nível de endividamento), as quais dependem de fatores econômicos contingenciais, é possível constatar a existência de capacidade estatal na gestão da dívida pública no Brasil, resultante da ação deliberada da burocracia econômica, levada a cabo ao longo de várias décadas e que permanece como traço hoje constitutivo do Estado brasileiro. Discussão: Os achados preliminares buscam contribuir com a literatura sobre capacidades estatais e afirmar sua utilidade analítica na medida em que permite dar conta de uma forma específica de poder, aquele exercido pela burocracia.
\end{abstract}

PALAVRAS-CHAVE: capacidade estatal; gestão da dívida pública; Secretaria do Tesouro Nacional; burocracia econômica; Estado brasileiro.

Recebido em 9 de Agosto de 2019. Aprovado em 26 de Março de 2020. Aceito em 31 de Maio de 2020.

\section{Introdução ${ }^{1}$}

\footnotetext{
${ }^{1}$ Este artigo é versão modificada e ampliada de trabalho apresentado no VIII Congresso do Grupo de Investigación em Gobierno, Administración y Políticas Públicas (GIGAPP) realizado em Madrid em setembro de 2017. Agradecemos aos comentários e sugestões dos pareceristas anônimos da Revista de Sociologia e Política.
}

$\mathrm{O}$ $\mathrm{s}$ estudos sobre capacidade estatal emergiram na literatura com o desenvolvimento das reflexões efetuadas pela Sociologia Política e pela Economia relativas à expansão, a partir de meados do século passado, das funções do Estado, tanto na área econômica, com a aplicação de políticas de cunho keynesiano, quanto na área social, com a consolidação do Welfare State. Nos países da América Latina e da Ásia, essa reflexão centrouse, sobretudo, em torno da capacidade estatal para promover o desenvolvimento por meio de processos de industrialização acelerada. São clássicos desse enfoque os trabalhos de Theda Sckopol (1979, 1985), Peter Evans (1992) Kathrin Sikkink (1991), Barbara Geddes (1994), esses últimos enfocando em particular o Brasil na perspectiva comparada com outros países.

Posteriormente, o tema reemerge em um contexto histórico distinto em termos econômico e ideológico. Relacionando-se à chamada crise fiscal do Estado que atinge particularmente os países endividados da periferia do sistema capitalista, ao longo dos anos 1980 e 1990 e à segunda geração de propostas de reformas de cunho neoliberal, voltadas não mais ao desmonte do Estado, mas à sua reestruturação, o conceito de capacidade estatal passa a ser discutido pelo enfoque da difusão de boas práticas de governança, como transparência, combate à corrupção, eficiência etc. (Schneider \& Doner, 2000). 
${ }^{2}$ Sem a intenção de desenvolver esse debate no âmbito do presente trabalho, cabe apenas relembrar que a literatura marxista tem formulação diferente, afirmando a problemática em termos de autonomia (relativa) do Estado capitalista frente aos interesses (imediatos) da classe burguesa ou de sua fração dominante (Ver a respeito, Poulantzas, 1968, 1977).
Nesse novo contexto, capacidade estatal não tem mais a ver com a questão de autonomia dos atores estatais, isto é, a habilidade de resistir à pressão de grupos sociais poderosos que buscam capturar o Estado para atender a seus interesses particulares, como é frequentemente entendida na literatura não-marxista ${ }^{2}$. Ao contrário, os trabalhos das últimas décadas discutem capacidade estatal pelo prisma da governança, isto é, da habilidade dos atores estatais de compartilhar a implementação de suas políticas e a operação de serviços públicos em parceria com atores na sociedade civil (organizações não governamentais e empresas privadas). No primeiro momento, quando o Estado é visto como "solução" para o desenvolvimento econômico, capacidade estatal significava autonomia para resistir às pressões dos grupos sociais (Evans, 1992); já na perspectiva de governança, quando o Estado passa a ser "problema", capacidade estatal será entendida como a habilidade da burocracia em compartilhar a gestão das políticas públicas com os atores da sociedade civil (onde estão as "boas" soluções). Em outras palavras, a problemática do conflito entre Estado $\mathrm{x}$ sociedade, que inicialmente permeou os estudos de capacidade estatal, é substituída por questões de boas práticas de governança na implementação de políticas públicas.

Mais recentemente, o tema ganha maior projeção na agenda de governos e nos meios acadêmicos que demonstram renovado interesse na análise e compreensão da 'policy capacity', considerando a crescente complexidade dos problemas contemporâneos de políticas públicas e as expectativas elevadas dos cidadãos que geram desafios sem precedentes para a capacidade dos governos de elaborar e implementar políticas públicas efetivas (Wu et al., 2015). A importância da temática se justifica ainda com o argumento de que as mudanças políticas de longo prazo e as diferenças duráveis de desenvolvimento econômico e social entre os países dependem de seus Estados e de como eles se tornam capazes de fazer crescer as rendas, estabelecer burocracias efetivas e prover adequadamente os serviços públicos.

Dessa forma, é importante esclarecer que os estudos sobre capacidades estatais justificam-se menos por sua potencialidade teórica em si de explicar a dinâmica das forças políticas (as quais, como se indicará a seguir, são précondições, que determinam a configuração ou não de capacidade estatal); tais estudos justificam-se, sobretudo, por sua eficácia prática no desenvolvimento econômico dos países e na mudança social duradoura, como já observaram argutamente alguns autores (Lindvall \& Teorell, 2016). Assim é que a introdução mais recente do tema no Brasil se fez não nos meios acadêmicos, mas sim por pesquisadores do IPEA (Instituto de Pesquisa Econômica Aplicada, think tank governamental encarregado de oferecer subsídios ao policy-making) em contexto de reinserção da temática de desenvolvimento como prioridade na agenda dos governos de Luiz Inácio Lula da Silva (2003-2010) e Dilma Roussef (2011-2016) e dentro de um perspectiva voltada para examinar os arranjos institucionais exigidos para uma efetiva implementação de políticas públicas (Gomide \& Pires, 2014; Gomide \& Boschi, 2016). Entendendo arranjos institucionais como o conjunto de regras, mecanismos e processos que definem a maneira como os diferentes atores se coordenam no processo de implementação, os estudos do IPEA enfatizam que os efeitos "capacitadores" dos arranjos institucionais residem justamente na ampla participação dos diferentes atores envolvidos ou afetados pela política em questão; ou seja, a ampla participação, e não o insulamento, é o que produz uma sinergia para a produção das políticas governamentais. É a partir dessa iniciativa dos pesquisadores do IPEA que o tema repercute para os meios acadêmicos, gerando pesquisas e publicações, como o dossiê da revista Sociedade e Cultura (2017), teses como Lima-Silva (2019), Lima (2019), e artigos como Souza (2017), Grin e Abrucio (2018), Miranda e Oliveira (2018). 
Não pretendemos realizar aqui uma revisão do debate sobre o tema, o que já tem sido feito por autores que assinalam vários problemas analíticos contidos nos estudos. Tais problemas se referem à ausência de uma definição teoricamente elaborada do conceito de capacidade estatal, sendo o termo utilizado frequentemente como mera expressão do senso comum e de forma polissêmica. As inconsistências envolvem ainda raciocínios tautológicos, ambiguidade nas relações de causalidade entre as variáveis e problemas de operacionalização e mensuração daí decorrentes. Sendo uma agenda de pesquisa mais vinculada a policymakers, a discussão carece de maior fundamentação teórica, gerando análises empíricas em que as variáveis que costumam ser usadas para definir capacidade - instituições, burocracia, infraestrutura - frequentemente são as mesmas usadas para determinar os resultados de capacidade (Cingolani, 2013; Kocher, 2010; Enriquez \& Centeno, 2012; Lindvall \& Teorell, 2016; Hanson \& Sigman, 2011; Wu et al., 2015).

Procurando superar tais problemas, Lindvall e Teorell (2016) destacam a dimensão de poder contida na temática de capacidade estatal, definindo esse conceito como uma relação causal entre instrumentos de política (sejam eles, coerção, propaganda ou incentivos financeiros) e resultados almejados pelos policymakers. Nessa relação causal, recursos (humanos, financeiros e de informação) podem ser utilizados para potencializar sua força. Portanto, assinalam que capacidade estatal não pode ser observada ou mensurada, mas apenas os instrumentos e recursos utilizados pelo Estado para alcançar os objetivos almejados.

Incorporando e redefinindo tais formulações, entendemos o conceito de capacidade estatal como a ação de agentes que mobilizam institucionalmente diferentes recursos (financeiros, humanos e informacionais) visando implementar políticas prioritárias do governo, tendo como condição prévia o apoio de forças ou grupos dominantes e a neutralização política de eventuais vetos.

Do ponto de vista conceitual, pode-se diferenciar a noção de poder atribuída aos líderes eleitos e a noção de capacidade estatal atribuída à burocracia e a suas habilidades ou competência técnica-operacional para executar as políticas públicas. Essa distinção não desconsidera que a burocracia seja um ator político, isto é, que exerce poder, conforme a clássica formulação weberiana; ao contrário, com a distinção pretende-se enfatizar que a burocracia exerce o poder de forma distinta daquela exercida pelos políticos eleitos. Portanto, do ponto de vista analítico, o estudo do tema de capacidade estatal, ou de construção de capacidade estatal recai sobre questões como recrutamento de quadros, estrutura de carreiras, orçamento disponível etc. de organizações burocráticas governamentais, recursos esses necessários ao exercício de ações implementadoras de políticas públicas em diferentes setores do aparato estatal. O que, aliás, constitui indicadores analíticos dos estudos citados anteriormente.

Várias precauções analíticas e conceituais devem ser tomadas pelos estudos sobre o tema. Assim, o conceito de capacidade estatal refere-se às características assumidas pela ação deliberada dos agentes governamentais e não pode ser confundido com indicadores de resultados, como PIB, por exemplo, os quais podem ocorrer independentemente da ação governamental. Além disso, capacidade não pode ser considerada também como um atributo fixo do Estado, mas contingente à luta política e variável conforme a correlação de forças existentes em um determinado contexto concreto. Ela se refere ainda a determinada área de ação governamental, o que explica as variações entre diferentes dimensões como, por exemplo, a capacidade de defender suas fronteiras, mas não de elevar o nível educacional da população, a capacidade coercitiva, mas não de desenvolvimento econômico etc. Dessas diferentes dimensões decorrem inclusive o próprio uso do conceito no plural. De acordo com tal perspectiva, os recursos 
financeiros, humanos e informacionais disponíveis ou disponibilizados pelo Estado para as diferentes áreas de sua atuação exprimem os objetivos almejados ou as prioridades estabelecidas por cada governo que comanda o aparato estatal. A partir dessas formulações, o modelo analítico que adotamos neste estudo pode ser visualizado na Figura 1.

A análise empírica se constitui de um estudo de caso da Secretaria do Tesouro Nacional (STN), órgão do Ministério da Fazenda criado em 1986, responsável pelo controle unificado do orçamento e pela gestão da dívida pública no país. A área fiscal permite observar de forma clara que os resultados, ou melhor, os indicadores aí apresentados, não dependem apenas da ação estatal, mas em grande parte de fator externo, qual seja, o crescimento ou não da economia. Em outras palavras, o estudo de caso da STN mostra o processo por meio do qual membros da alta burocracia econômica decidiram, no contexto de esgotamento das alternativas anteriores de financiamento das atividades governamentais, de pressões de organismos internacionais e o respaldo de atores políticos internos, construir um conjunto de recursos necessários ao alcance dos objetivos que se tornaram prioritários naquele momento: assim formaram e desenvolveram a capacidade do Estado brasileiro nessa área.

O material empírico apresentado como base da análise se divide em elementos qualitativos e quantitativos: os primeiros são constituídos por depoimentos dos atores envolvidos no processo de criação da STN, que revelam a percepção que tinham sobre o novo contexto econômico e político em que se encontrava o país naquele momento histórico e que explicam a priorização da questão fiscal na agenda governamental. Com tais depoimentos, procuramos demonstrar a intenção deliberada dos agentes em criar ou ativar institucionalmente recursos (financeiros, humanos e informacionais) que capacitassem o Estado brasileiro para gerir de maneira centralizada o orçamento e o endividamento público, e inclusive demostrar transparência das contas públicas para os novos credores/financiadores das atividades estatais. Os elementos quantitativos referem-se à sistematização por meio de estatística descritiva de dados relativos à: i) expansão de áreas dentro do aparato estatal relativas às finanças públicas (por meio da criação e subdivisão de órgãos e ampliação e valorização das carreiras e cargos; ii) criação e desenvolvimento de sistemas informacionais para garantir a capacidade de gestão daquela área específica; iii) e, ainda, dados relativos à Lei Orçamentária Anual (LOA) que evidenciam a expressiva parcela do orçamento (receitas e despesas) que passa pela gestão da dívida mobiliária federal dentro do STN.

O texto a seguir está assim organizado: após a primeira parte, introdutória, a parte II oferece uma breve contextualização da criação da STN no bojo da crise da dívida externa dos anos 1980, quando técnicos situados nos altos escalões dos órgãos econômicos do Estado entenderam que as respostas para os proble-

Figura 1 - Modelo Analítico envolvendo decisão política, arranjo institucional e capacidade estatal efetiva

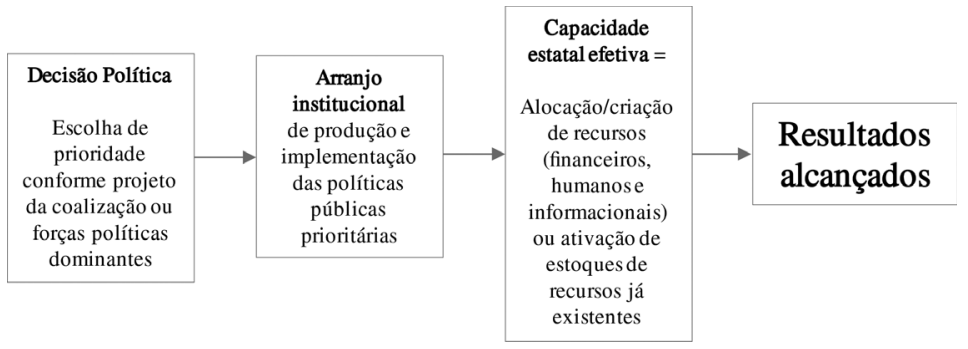

Fonte: Elaboração própria. 
mas então colocados passavam pela criação e fortalecimento institucional de um órgão específico para gerir as finanças públicas do país. Tal fortalecimento está associado às necessidades de controle sobre a estrutura orçamentária do Estado e ao peso crescente do endividamento público (sobretudo interno, a partir dos anos 1990) no financiamento das atividades estatais. Junto a esta contextualização, são trazidos depoimentos de atores-chave que em diferentes momentos históricos estiveram aí envolvidos, o que lhes permite dar, conforme nosso esquema analítico, o mais completo entendimento do processo de construção dos arranjos institucionais que viabilizaram a criação da STN. Na terceira parte o texto apresenta dados quantitativos referentes à expansão e diversificação dos quadros e carreiras burocráticas dentro da STN e à criação de recursos informacionais para a gestão fiscal no país, perpassando uma trajetória temporal até o presente; nessa terceira parte são apresentados também dados que demonstram a magnitude dos recursos movimentados pela STN por meio da gestão da dívida pública mobiliária federal. As considerações finais apontam inferências que podem ser extraídas desse caso como contribuição para o debate sobre a validade analítica do conceito de capacidade estatal e para futuros trabalhos na área.

\section{Breve contexto histórico da criação da STN: crise da dívida e ajuste fiscal no Brasil}

\footnotetext{
${ }^{3}$ Como é sabido, o Brasil passou durante os governos militares por altas taxas de crescimento econômico via endividamento externo, mas se viu, ao final dos anos 1970 , em completa desorganização contábil e financeira e com esgotadas possibilidades de financiamento externo (Gouvêa, 1994). No bojo desse processo ocorreu a ruptura do mercado de crédito internacional, que até então havia sido uma importante
}

A partir do final dos anos 1970, as transformações do capitalismo internacional, que levaram à desregulação e liberalização das finanças e mudança dos paradigmas econômicos, foram acompanhadas por transformações nas estruturas administrativas dos Estados Nacionais. Inserido nesse processo, embora marcado por diversas particularidades, o Estado brasileiro passou a sofrer de uma série de disfuncionalidades entre a estrutura administrativa responsável pelo seu orçamento, de um lado, e o esgotamento do modelo de desenvolvimento que, a partir desse momento, passou a impor uma série de ajustes ${ }^{3}$. Tais disfuncionalidades eram percebidas pelos organismos internacionais, que pressionavam pela necessidade de centralizar a estrutura de receitas e despesas do Estado, aumentando a capacidade de controle estatal sobre o orçamento. Assim, os chamados ajustes estruturais impostos aos países endividados, especialmente na América Latina (Haggard \& Kaufman, 1993) foram caracterizados não apenas por pressões em favor de privatizações e medidas de liberalização, como também por pressão em favor de medidas de contenção fiscal. O que estava em curso naquele momento era uma mudança nos padrões de desenvolvimento desses países, o que se refletia em mudanças nas estruturas estatais. A Tabela 1 revela que não só houve uma inversão na ação econômica do Estado brasileiro a partir da década de 1980, mas também que essa inversão se manteve como tendência desde então.

Tabela 1 - Evolução dos gastos com investimentos públicos (exceto estatais) e com pagamento de juros do Setor Público (em \% do PIB $)^{\mathrm{I}}$

\begin{tabular}{lcccccccc}
\hline & $\mathbf{1 9 4 7 - 6 3}$ & $\mathbf{1 9 6 4 - 6 9}$ & $\mathbf{1 9 7 0 - 8 4}$ & $\mathbf{1 9 8 5 - 9 4}$ & $\mathbf{1 9 9 5 - 9 8}$ & $\mathbf{1 9 9 9 - 0 2}$ & $\mathbf{2 0 0 3 - 0 8}$ & $\mathbf{2 0 0 9 - 1 3}$ \\
\hline Receita Corrente & 18,5 & 21,4 & 24,6 & 27,4 & 37,0 & 39,8 & 41,6 & 40,9 \\
Investimentos $^{\text {II }}$ & 3,5 & 4,5 & 3,2 & 3,1 & 2,3 & 1,9 & 1,9 & 2,8 \\
Juros $^{\text {III }}$ & 0,6 & 0,3 & 1,4 & 4,4 & 6,9 & 10,1 & 9,8 & 7,7 \\
\hline
\end{tabular}

Fonte: Marconi (2017).

${ }^{\mathrm{I} O s}$ dados aqui apresentados foram coletados e calculados por Nelson Marconi, que gentilmente autorizou sua reprodução. Foram extraídos de um quadro mais amplo, publicado na edição de fevereiro (2017) da Revista Conjuntura Econômica da FGV. ${ }^{\mathrm{II}} \mathrm{O}$ período de alta inflação produz distorções no cálculo dos investimentos públicos, sendo seu valor real nesse período provavelmente menor do que o mostrado acima.

IIIExclui a correção monetária entre 1970-94. 
fonte líquida de financiamento público. A partir desse momento a dívida pública interna torna-se uma importante fonte de financiamento do Estado ao mesmo tempo em que se esgotavam as possibilidades de crescimento puxado pelos investimentos públicos.

${ }^{4} \mathrm{O}$ texto comemorativo dos 20 anos do STN foi redigido por Alcides Ferreira que também fez várias entrevistas com os membros da Secretaria.
Como se pode observar, a partir da década de 1980 aumenta significativamente o gasto com juros, tendência que se acentua ainda mais a partir do fim da inflação, com o Plano Real. Por outro lado, a retomada dos investimentos públicos não ocorreu. Embora tenham experimentado um significativo aumento após 2008, ainda ficam abaixo dos padrões das décadas de 1960 e 1970 . O que se nota é, portanto, uma mudança qualitativa nas componentes do gasto estatal, o que, independentemente dos "determinantes" que cada tipo de análise tenda a elas atribuir, sem dúvida se reflete na estrutura do Estado.

Assim, na década de 1980, o diagnóstico geral era o de que havia um esgotamento do padrão de intervenção estatal e a necessidade de uma profunda reorganização administrativa do Estado brasileiro. Pesava em sua defesa a necessidade de deslocar os centros de decisão no aparelho estatal, já que a configuração institucional herdada do regime militar havia permitido a concentração de poder em esferas insuladas, descoordenadas e isentas da necessidade de prestação de contas para o sistema político e a sociedade como um todo, embora bastante porosas frente a interesses setoriais (Codato, 1997).

Essa desorganização e falta de controle administrativo e contábil se tornou especialmente evidente quando o país foi obrigado a negociar com o FMI (Fundo Monetário Internacional) e com credores privados. Como relatado no documento comemorativo dos 20 anos de criação do STN:

As negociações com o FMI, a partir de 1983, deixaram claro que as relações entre Banco do Brasil, Banco Central e Tesouro tinham que mudar. O desarranjo institucional tornava inadministráveis as finanças públicas brasileiras (STN, 2006, p. 77) ${ }^{4}$.

Foi nesse contexto que um grupo de técnicos dos Ministérios da Fazenda, do Ministério do Planejamento, Orçamento e Gestão (MPOG), do Banco do Brasil e do BACEN (Banco Central) se articulou em torno da urgente necessidade de reordenamento institucional dos órgãos responsáveis pelas finanças públicas. Por meio do voto 283/1984 do Conselho Monetário Nacional (CMN), de 21 de agosto de 1984, designou-se uma comissão para tratar do assunto e propor linhas concretas de ação, que ficou conhecida como "Comissão para o Reordenamento das Finanças". O documento produzido pelo grupo propunha as seguintes mudanças:

(1) incluir no Orçamento da União todos os gastos do Governo; (2) fazer com que o BC se tornasse um banco central clássico, focado no controle da moeda, eliminando suas funções de fomento; (3) passar a gestão da dívida pública para a Fazenda e, (4) redefinir o papel do Banco do Brasil, que passaria a ser um banco comercial (STN, 2006, p. 80).

Ficou claro, naquela ocasião, que os técnicos não dispunham sequer dos dados para apurar o déficit público, já que a execução orçamentária era difusa, descentralizada, passando por diversas entidades governamentais. Além da falta de controle e coordenação, a própria ausência de indicadores e dados é em si um indício de ausência de recursos de capacidade estatal, como aponta a literatura (Enriquez \& Centeno, 2012). Nesse caso, faltava capacidade de controle sobre a estrutura de receitas e despesas públicas. Diante disso, a centralização em um único órgão de atividades que antes se dispersavam entre o Banco Central e o Banco do Brasil, e a produção de informações e estatísticas precisas eram medidas tidas como indispensáveis ao controle das finanças públicas. Essa era a visão que orientava a ação do grupo de técnicos envolvidos no processo, que afirmavam não agir apenas em respostas às pressões do FMI. O texto comemorativo dos 20 anos da STN é claro nesse sentido:

Mas é um engano achar que essas mudanças ocorreram por pressão do FMI. "Isso foi predominantemente a percepção dos técnicos, especialmente do quadro permanente do Governo, de que era fundamental, crucial, que se 
desse alguma organização às finanças públicas, como forma de dar um equilíbrio macroeconômico", afirma o ex-Ministro do Planejamento, João Batista de Abreu, que era chefe da Assessoria Técnica do Ministério do Planejamento (STN, 2006, p. 80 - grifos nossos).

Em trabalho sobre a ação desse grupo de técnicos, Gouvêa (1994) afirma que seu protagonismo e sua disposição em arregimentar apoios políticos foi fundamental para a reorganização administrativa da área econômica do Estado brasileiro. Um dos resultados do trabalho do grupo, como se sabe, foi a criação da STN. Todavia, o processo de reorganização do aparato estatal responsável pelas finanças públicas foi marcado por embates e disputas de todo tipo, passando pela resistência da burocracia de instituições que perderiam poder, ou alegavam que o perderiam, como o Banco do Brasil, até questionamentos na Justiça sobre a legalidade das medidas propostas. O texto abaixo é ilustrativo:

Representantes de cada ministério ou órgão de hierarquia equivalente formaram a equipe da STN. Como explica Andrea Calabi, que assumiu o posto de primeiro Secretário do Tesouro, o objetivo foi uma composição política entre o Ministério da Fazenda e o do Planejamento, além dos outros órgãos. As tarefas pela frente seriam duras. Era preciso angariar apoio. Duas outras razões para trabalhar inicialmente com essa elite de servidores da Fazenda, do Planejamento, do BC e do BB foram a inexistência, naquele momento, de uma carreira funcional do Tesouro e a necessidade de quadros com experiência que pudessem desempenhar suas funções no menor prazo possível (STN, 2006, p. 96).

O processo, portanto, foi longo e enfrentou todo tipo de resistência, buscando como resultado a construção de recursos administrativos e de poder decisório em torno da STN, órgão concebido, desde sua criação, como lócus que deveria ser capaz de se blindar das pressões difusas na sociedade e no próprio corpo político, como atesta o seguinte depoimento:

"Era conveniente que o novo Presidente da República tomasse posse com um arranjo institucional nas finanças públicas que lhe protegesse das naturais pressões políticas”, escreveu Maílson da Nóbrega (STN, 2006, p. 83).

Vale frisar que a ação deliberada dos agentes governamentais responsáveis pelo movimento de reformas institucionais foi de fundamental importância no processo de construção de capacidade estatal na área da dívida pública. No entanto, esse processo não se deu de maneira apartada de um movimento mais global pelo qual outros países capitalistas também passavam, marcado pelo aumento da importância do endividamento público como forma de financiamento dos Estados e como indicador de estabilidade macroeconômica. O nexo entre esse processo de reorganização econômica internacional e o aumento do endividamento dos países é inegável, pois foi notável o aumento da dívida pública em relação ao PIB em diversos países ao longo das décadas de 1970 e 1980. Se tomarmos o exemplo dos Estados Unidos, veremos que sua dívida pública cresceu 28,5\% (em termos nominais) entre os anos 1948-1969, enquanto no período subsequente, isto é, 1970-1991, o salto é de $821 \%{ }^{5}$.

Foge ao escopo desse trabalho discutir tais teses bem como desenvolver explicações teóricas sobre os nexos entre financeirização e aumento do endividamento dos países ${ }^{6}$. Cumpre apenas apontar que o aumento generalizado das dívidas públicas foi acompanhado pelo desenvolvimento e circulação internacional daquilo que o Banco Mundial chamou de "Melhores Práticas Internacionais" de gerenciamento da dívida, produzindo efeitos sobre a configuração institucional dos órgãos estatais responsáveis por esse setor, exigindo-lhes o provimento de habilidades técnicas e operacionais. $\mathrm{O}$ caso aqui em análise criação e desenvolvimento institucional da STN no Brasil - faz parte, portanto, de um processo mais amplo, ocorrido no conjunto do sistema capitalista inter-

nacional.

${ }^{6}$ Há diversas explicações na literatura de economia internacional a respeito da estratégia de endividamento daquele país, adotada na década de 1970, como a de Hirsch (2010), Krippner (2011), Arrighi (2013).

${ }^{5}$ Os dados são do FMI, aqui reproduzidos pelo IPEA 
7 A referência utilizada aqui nas próximas passagens (Caputo Silva et al., 2009) trata-se de um livro organizado e publicado pela própria Secretaria do Tesouro Nacional, composto por capítulos escritos pelo seu corpo técnico e com apoio do Banco Mundial. Por nos interessar aqui frisar que a instituição STN é a portadora de certas visões e diagnósticos aqui apresentados, referenciaremos tal material como STN \& Banco Mundial (2009).

${ }^{8}$ Em geral, tais crises se deram por conta de problemas nos Balanços de Pagamentos dos países, materializando-se em crises cambiais e, indiretamente, fiscais. No caso brasileiro, a desvalorização cambial ocorrida em 1999 aumentou sobremaneira a dívida pública, já que parte dela era composta de títulos indexados ao câmbio.
Foi na esteira desse processo que ocorreu, na passagem dos anos 1980 para 1990, a chamada primeira onda do processo internacional de profissionalização da administração da dívida pública, quando países como Nova Zelândia, Bélgica, Irlanda, Dinamarca, Suécia, entre outros, empreenderam processos de integração de suas dívidas interna e externa e estruturaram departamentos de administração da dívida mais centralizados (Wheeler, 2004).

Já na metade da década de 1990 ocorreu a chamada segunda onda de reformas institucionais ligadas à administração da dívida pública, que envolveu os chamados países emergentes e contou com a influência de organismos multilaterais como FMI e BIRD (Caputo Silva et al., 2009) ${ }^{7}$, que atuaram fortemente frente a vulnerabilidade externa pela qual passaram tais países, evidenciada pela sequência de crises: no México em 1994, a asiática em 1997, a russa de 1998 e a brasileira de 1999. Tais crises, embora tenham sido em geral crises externas e cambiais, produziram aumento do endividamento público ${ }^{8}$. Cabe ressaltar aqui as recomendações efetuadas pelos organismos financeiros internacionais sobre a importância de se ter mercados de dívida pública "mais sólidos e gerenciamentos mais profissionais", como se expressou o corpo técnico da Subsecretaria da Dívida Pública (STN \& Banco Mundial, 2009 p. 443). De acordo com artigo elaborado pelo próprio corpo técnico da STN, as crises financeiras da década de 90 e a globalização do capital, que inclui desregulamentações e inovações financeiras, "impuseram novos requerimentos em termos de capacidade técnica a gestores de dívida em geral” (idem, p. 443). Assim, a "profissionalização" da gestão das dívidas públicas colocou-se também como a necessidade de prover habilidades técnicas e operacionais nessa esfera.

Além disso, de maneira estreitamente ligada "ao processo de profissionalização da gestão da dívida pública" veio o "ímpeto para o desenvolvimento do mercado doméstico de dívida pública” (STN \& Banco Mundial, 2009, p. 18). Portanto, o que se assistiu nesse momento de crises e de grande vulnerabilidade externa dos países periféricos foi a clara configuração de uma estratégia voltada à criação de incentivos para o desenvolvimento desse mercado doméstico de dívida pública, reduzindo a dependência de empréstimos bancários e externos e ampliando a capacidade de endividamento estatal por intermédio desse mercado de capitais.

Assim, o processo de reorganização das finanças públicas pode ser entendido como resultante da ação deliberada de um grupo de técnicos bem situados nos órgãos do Estado e que, partindo de um determinado diagnóstico dos problemas administrativos e econômicos, construiu apoio para reorganizar a relação entre órgãos estatais e centralizar certas funções em um único órgão, a STN. Esse órgão, como demonstraremos, passou por um constante fortalecimento e aperfeiçoamento institucional decorrente de outros dois processos distintos, mas intrinsecamente correlacionados: i) Aumento da importância da dívida pública, tanto como forma de financiamento estatal como por sua interdependência frente às demais variáveis macroeconômicas, o que, no novo contexto de capitalismo globalizado, a torna um indicador de fundamental importância para a manutenção de estabilidade macroeconômica e de credibilidade frente aos investidores: ii) Necessidade, daí decorrente, de controle centralizado sobre o orçamento e sua transparência pública.

A seguir analisaremos mais de perto o processo de mobilização de recursos para efetivar a capacidade de gestão da dívida pública no Brasil, o que viabilizará, como resultado, um modelo de financiamento dos gastos públicos no qual a dívida pública mobiliária federal adquire papel fundamental. 


\section{Mobilização de recursos para efetivar a capacidade de gestão da dívida pública no Brasil}

Como indicamos anteriormente, a construção do potencial para efetivar a capacidade estatal se dá através da mobilização de diferentes recursos (financeiros, humanos e ainda informacionais) visando levar a cabo os objetivos, decisões ou políticas públicas priorizadas pelos governantes em um determinado momento e dentro de contextos específicos. Tendo apontado o contexto dentro do qual a questão da dívida pública ganha enorme centralidade na agenda governamental, analisaremos, nessa parte, o processo de centralização de decisões sobre as contas públicas do país na STN, órgão criado em 1986 e alocado dentro do Ministério da Fazenda, com as atribuições de planejar, coordenar e controlar a programação financeira do governo, viabilizando um orçamento unificado.

III.1. Mobilização de recursos humanos: Qualificação técnica e valorização de carreira dos gestores da dívida pública

Refletindo a importância crescente assumida pela STN, destaque inicial deve ser dado ao notável esforço de capacitação profissional de seus quadros, marcado, sobretudo, pela difusão de um saber internacionalizado sobre práticas de gestão da dívida pública (STN \& Banco Mundial, 2009). Assim, os técnicos da STN visitaram os Estados Unidos, México e diversos países da Europa, com o intuito de analisar as respectivas estruturas de gestão da dívida pública. Eis como o relatório da STN, publicado pelo IPEA, descreve esse processo:

Começou aí o processo de convergência entre a estrutura de administração da dívida da STN e o que o Banco Mundial denominaria em documentos posteriores de "melhores práticas internacionais (STN \& Banco Mundial, p. 439-440).

A construção de recursos técnicos foi paulatina, já que os primeiros quadros de funcionários da STN eram compostos de profissionais provenientes dos órgãos envolvidos em sua criação (Banco do Brasil, Caixa Econômica Federal, Banco Central, ou do próprio Ministério da Fazenda). Já no ano de 1987, por meio do Decreto-Lei $\mathrm{n}^{\circ}$ 2.346, ocorre a criação da carreira de Finanças e Controle na Administração Pública Federal, que incluía analistas (nível superior) e técnicos (nível médio). O primeiro concurso para essa carreira, entretanto, só ocorreria em 1989, pouco antes da posse de Collor, governo marcado por uma paralisia nas contratações de pessoal pelo governo federal. Assim, em fins de 1992, haviam sido realizados apenas dois concursos para a carreira, "sendo que $82 \%$ dos servidores selecionados no último deles já haviam deixado a instituição, inclusive em razão da forte deterioração salarial característica do período Collor" (IPEA, 2010, p. 441)

Com a recuperação da estrutura do Estado brasileiro desorganizada pelo governo Collor, ocorrida de forma paulatina a partir de 1994, junto ao processo de implementação do Plano Real, começam a ser tomadas medidas destinadas a recuperar os salários da carreira de analista e atrair profissionais de mais alta qualificação. Nesse ano de 1994, a STN desenvolveria um sistema de remuneração variável denominado Gratificação de Desempenho e Produtividade (GDP), que seria paga conforme avaliação institucional e individual de cada servidor.

Ainda em 1994 seria publicado o primeiro regimento interno da STN com a formalização das funções e atribuições de cada unidade do Tesouro. Neste mesmo ano ocorreria a separação das atividades de controle e auditoria do Tesouro, por meio da criação da Secretaria Federal de Controle, inicialmente subordinada ao Ministério da Fazenda (Medida Provisória n 480, de 27 de abril de 1994) (IPEA, 2010, p. 442). 
No que diz respeito à valorização do corpo técnico da STN, vale ressaltar que após 1995 não se realizaram mais concursos para nível médio, apenas superior. A recuperação salarial e o aumento do prestígio que começa a ser identificado com a carreira expressam-se no crescimento da relação candidato-vaga observada nos diferentes concursos realizados para a STN, a partir dessa época (Tabela 2).

Outro elemento que se destaca é a tendência de ampliação de pessoal responsável pelas crescentes tarefas a que a STN é incumbida, aumentando $50 \%$ entre 2002 e 2007, passando de 20 para 30 profissionais. Embora o quantitativo de pessoal seja baixo, o que se deve à natureza concentrada de suas atividades, diferente, por exemplo, da Receita Federal, é importante enfatizar que o processo de seleção é altamente competitivo e dirigido a profissionais com sólida formação na área de economia e finanças (STN \& Banco Mundial, 2009). Reforça essa observação o alto nível de qualificação (background educacional) dos Secretários do Tesouro, desde a sua criação. De um universo de 14 diretores que passaram pela STN no período, apenas um não tinha título de pós-graduação. Do total, 5 eram doutores (35\%), 4 fizeram especialização $(28 \%)$ e $5(35 \%)$ cursaram algum tipo de pós-graduação em universidades americanas, todas na área de economia e finanças 9.

\section{III.2. Mobilização de recursos informacionais: Implantação de sistemas de informação}

9 Todos possuem algum grau de circulação por outros órgãos da burocracia econômica (sobretudo por outras secretarias do Ministério da Fazenda) e muitos ocuparam posições no mercado. A análise de suas trajetórias de carreira, entretanto, foge ao escopo deste artigo (cf. Dantas, Montrose, Calabrez \& Codato, 2017).
Como já enfatizamos aqui, a desorganização contábil e financeira do governo, com orçamento difuso, multiplicidade de contas bancárias e falta de controle e informações confiáveis, foi o que levou à criação da STN. Para efetivar as atribuições do STN, foi implantado conjuntamente com esse órgão, um sistema de execução financeira do orçamento que deu origem, menos de um ano depois, ao Sistema Integrado de Administração Financeira do Governo Federal (SIAFI), cujas funções seriam:

integrar os sistemas de orçamento, execução financeira e contabilidade; utilizar tecnologia mais avançada, incluindo o processamento on-line de transações; centralizar e padronizar os procedimentos relacionados à execução do orçamento; ser obrigatório para a administração direta, e permitir a implantação de uma conta única do Tesouro. Da concepção à lógica, o Siafi nasceu pelo engenho daquele pequeno grupo de novos servidores da STN (STN, 2006, p. 96).

Sua criação foi bem sucedida e hoje todas as entradas e saídas de dinheiro passam pelo orçamento unificado e pelo sistema informatizado da STN. Uma consequência evidente desse processo de reorganização da estrutura do Estado é o aumento da capacidade de controle do Ministério da Fazenda sobre as finanças públicas.

Sistemas informais sobre estratégia de gestão da dívida pública e gerenciamento de riscos também têm sido constantemente desenvolvidos. Um exemplo é o aperfeiçoamento de modelos estocásticos utilizados para análise do mercado e de refinanciamento Cost-at-Risk (CaR) e Cash-Flow-at-Risk (CfaR), aprimoramento de sistemas de processamento e análise de dados além do

Tabela 2 - Relação Candidato-vaga em concursos para o quadro técnico da STN

\begin{tabular}{lc}
\hline Ano & Relação Candidato-vaga \\
\hline 2002 & 37 \\
2005 & 82 \\
2008 & 107 \\
\hline
\end{tabular}

Fonte: elaboração própria, com base IPEA (2010). 
"desenvolvimento de novas ferramentas computacionais com o objetivo de facilitar a realização de exercícios de simulação de gerenciamento de passivos" (STN \& Banco Mundial, 2009, p. 141). Uma dessas ferramentas é o chamado Sistema de Planejamento Estratégico e Gerenciamento de Riscos (Gerir), em funcionamento desde 2002 e que visa subsidiar a elaboração e análise de estratégias alternativas de emissão de dívida com base em prospecção de cenários. O conhecimento especializado e de nível técnico avançado é acompanhado pela criação e implementação de ferramentas computacionais que dão suporte tecnológico às funções operacionais da STN, num processo de criação e aperfeiçoamento contínuo. Vale lembrar que todo esse desenvolvimento está, como afirma seu corpo técnico, em consonância com diretrizes que são elaboradas e difundidas pelo FMI e Banco Mundial, para quem "a administração da divida pública também deverá estar respaldada por um sistema de informação preciso e seguro" (STN \& Banco Mundial, 2009, p. 144 - grifos no original).

Sintetizando, todo esse movimento de fortalecimento da estrutura institucional da STN, ocorreu mediante três dimensões: i) a criação de subsecretarias, divididas, por sua vez, em coordenadorias gerais responsáveis por tarefas cada vez mais complexas e especializadas; ii) valorização de seu corpo técnico, com programas de expansão de carreira, elevação de salários e atração de mão de obra qualificada, dotada de alto nível técnico; iii) criação de um sistema informacional para acompanhamento e controle das contas públicas não só da União, mas a partir da Lei de Responsabilidade Fiscal, também dos demais entes federativos; e sobretudo para sinalizar ao mercado financeiro, comprador de títulos públicos, a situação destas finanças, garantindo-lhe credibilidade.

Por fim, importa destacar que a atividade de gestão da dívida é marcada por um caráter altamente técnico, que exige conhecimentos específicos e um conjunto de informações precisas e detalhadas. Pela própria natureza dessa atividade, seus técnicos a realizam de maneira insulada frente a outros órgãos do Executivo Federal, embora fortemente inserida no mercado financeiro, ambiente que dispõe dos recursos que são essenciais à sua atividade. Dessa maneira, podemos afirmar que sua atividade operacional, se por um lado se dá desvinculada das exigências político-partidárias (independente da coalizão do governo), por outro, é realizada com base em um universo de referência, que é o mercado.

III.3. Centralização orçamentária e criação de capacidade de gestão da dívida pública

A crescente importância da dívida pública mobiliária do Estado brasileiro, tanto por seu papel de financiadora dos gastos estatais como por sua interdependência em relação à macroeconomia, trouxe consigo a exigência de aprimoramentos nas suas formas de gestão. Isso é explicitamente afirmado em documento elaborado como "esforço coletivo" do próprio corpo técnico da STN responsável pela gestão da dívida e publicado pelo Ipea em 2010, conforme palavras abaixo transcritas:

A crescente relevância da DPF [Dívida Pública Federal] no conjunto do endividamento público brasileiro contribuiu para a ampliação da capacidade de gestão da União. A paulatina concentração da administração da dívida federal pela Secretaria do Tesouro Nacional acompanhou e reforçou estes processos (IPEA, 2010, p. 435).

Essa relação fica ainda mais clara quando olhamos para o peso que a dívida possui no financiamento do Estado, o que nos dá noção do montante que a STN precisa operar, em termos de fluxo e estoque dessa dívida, isto é, pagamento dos juros e rolagem do principal. Para que tenhamos uma noção da fatia que a dívida pública ocupa no orçamento federal, vale olhar para a LOA de 1999 (Gráfico 1), 


\author{
10 A Constituição de 1988 \\ estabeleceu o atual sistema de \\ planejamento e orçamento, \\ criando o PPA (Planejamento \\ Plurianual) de políticas \\ públicas, que estabelece os \\ objetivos, diretrizes e metas da \\ administração federal e se \\ articula com a execução dos \\ orçamentos anuais, prevista na \\ LOA. A LDO (Lei de \\ Diretrizes Orçamentárias) \\ intermedeia esse processo. \\ Assim, tudo o que o Estado \\ brasileiro prevê arrecadar e \\ gastar ao longo do ano deve \\ ser incluído na LOA. Não há \\ mais, como outrora, recursos \\ extraorçamentários
}

ano em que se construiu o atual arranjo coordenativo de política macroeconômica, o chamado tripé macroeconômico. ${ }^{10}$

O Gráfico 1 nos ajuda a dimensionar a quantidade de recursos que o Estado brasileiro, por meio da STN, capta no mercado, via colocação de títulos públicos. Essa opção de financiamento por meio do endividamento interno passou a ser central após a crise da dívida externa (1982), como já dito, quando foram interrompidas as fontes externas de financiamento, e mantém centralidade desde o lançamento do Plano Real, quando a dívida pública adquiriu estreita relação com a política macroeconômica. Essa proporção sofre pequenas oscilações ao longo dos anos fiscais, experimentando uma pequena redução nos anos 2000, embora sua importância não tenha se alterado substancialmente, como revela uma análise da LOA de 2010, mais de dez anos depois e já no final do governo Lula (Gráfico 2). O mesmo se revela pelo lado das despesas (Gráfico 3).

Gráfico 1 - Receitas da União por fonte e categoria econômica para o exercício financeiro de 1999

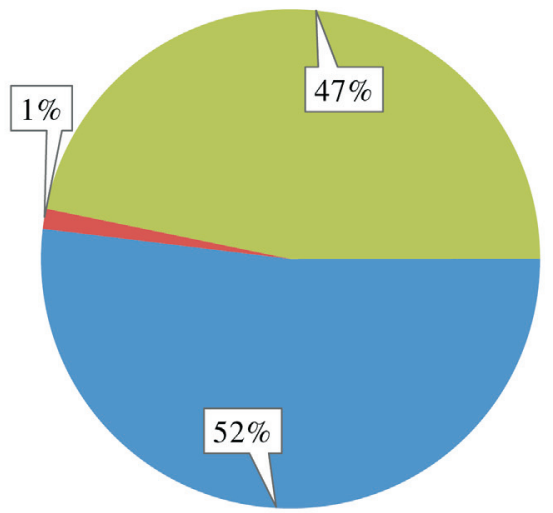
- Receita total do Tesouro Nacional (receitas correntes + receitas de capital)

Receita da administração indireta (estatais, fundos e fundações)

- Receita proveniente de emissão de dívida [contratual e mobiliária (emissão de título)]

Fonte: elaboração própria, com base em LOA, disponível em http://www.orcamentofederal.gov.br/

Gráfico 2 - Receitas da União por fonte e categoria econômica para o exercício financeiro de 2010

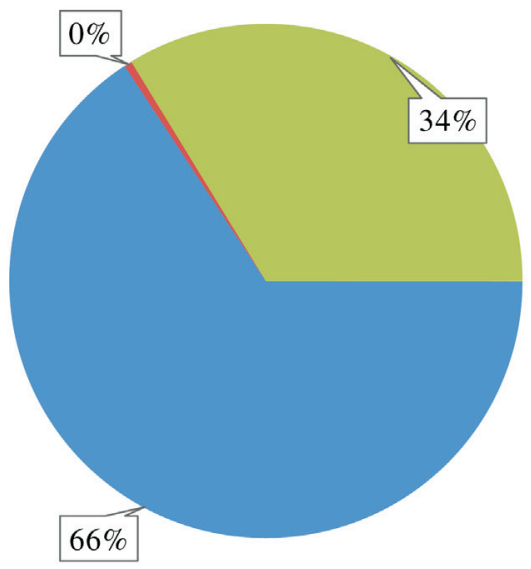

- Receita total do Tesouro Nacional (receitas correntes + receitas de capital)

- Receita da administração indireta (estatais, fundos e fundações)

$\square$ Receita proveniente de emissão de dívida [contratual e mobiliária (emissão de título)]

Fonte: elaboração própria, com base em LOA, disponível em http://www.orcamentofederal.gov.br/ 
Gráfico 3 - Despesas totais da União e despesas com a Dívida Pública

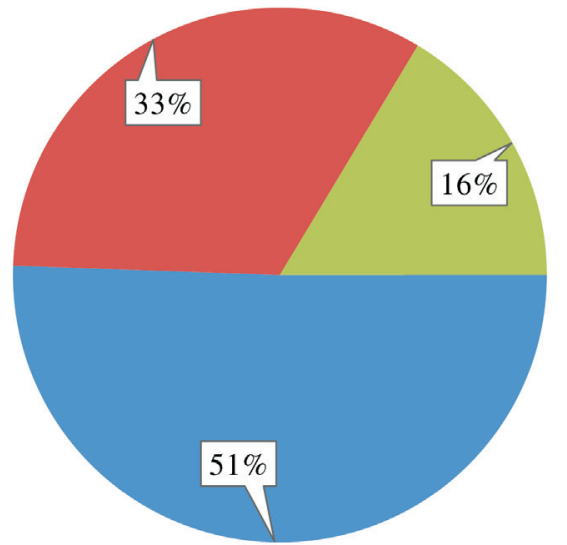

- Soma de todas as outras despesas (inclusive repasses a Estados e municípios)

- REFINANCIAMENTO DA DÍVIDA PÚBLICA MOBILIÁRIA FEDERAL

Despes as com encargos financeiros (juros)

Fonte: elaboração própria, com base em LOA, disponível em http://www.orcamentofederal.gov.br/

O Gráfico 3, além de demonstrar o peso que a rolagem da dívida possui no

${ }^{11}$ Aqui convém esclarecer que a rubrica "refinanciamento da dívida" não significa que esse montante saia do orçamento fiscal. Ele significa apenas que títulos foram emitidos para refinanciar o principal da dívida, isto é, títulos venceram ou foram resgatados, mas outros foram emitidos, gerando o mesmo montante em receita, o que não altera o estoque da dívida pública. A rolagem do principal é calculada pela equipe da Secretaria responsável pela dívida e consta no Plano Anual de Financiamento (PAF).
12 Art.1: "Fica atribuída ao orçamento brasileiro ${ }^{11}$, evidencia a importância da tarefa da STN, já que todo o cálculo e execução do refinanciamento da dívida (cor vermelha), mais a execução das despesas com juros (cor verde) passam por essa secretaria. Toda a gerência dessa dívida, que movimenta diariamente uma quantidade elevada de recursos, por meio da colocação e da rolagem de títulos do Tesouro Nacional no mercado financeiro, necessita de um órgão administrativamente competente, com fortes capacidades técnicas e operacionais. O próprio planejamento da composição (indexadores e prazos) do montante a ser captado, via mercado, no exercício financeiro (12 meses), tal como consta na LOA, já é uma evidência de recursos de capacidade técnica desse órgão, o que contrasta fortemente com a ausência de planejamento e indicadores precisos reinante nos anos 1980.

Assim, a gestão da dívida pública, totalmente centralizada na STN, envolve complexas tarefas administrativas que incluem estudos sobre a composição da dívida, estratégias de financiamento e gestão de riscos. O resultado desses estudos e projeções realizados pelo corpo técnico da STN são divulgados anualmente no Plano Anual de Financiamento da Dívida Pública (PAF), publicação que apresenta os objetivos, as diretrizes, estratégias e metas da instituição para o ano fiscal seguinte (Silva, Meneses \& Medeiros, 2009, p. 115). O PAF é apresentado anualmente no Comitê de Gerenciamento da Dívida Pública Federal, composto pelo Secretário-Adjunto da Dívida Pública, que o preside, e pelos coordenadores gerais e coordenadores da Secretaria Adjunta. As reuniões do comitê, no entanto, são realizadas mensalmente, já que se faz necessário discutir mês a mês as variações na conjuntura e são propostas estratégias de emissão da DPF para o mês seguinte. As decisões e estratégias ali estabelecidas são levadas ao Secretário do Tesouro que, se aprová-las, ainda as leva ao Ministro da Fazenda para avaliação e aprovação final. As propostas do comitê possuem, portanto, caráter propositivo, já que dependem da anuência do Secretário do Tesouro e, em última instância, do Ministro da Fazenda, conforme esclarecimentos da técnica do STN, Karla Rocha (STN \& BIRD, 2009, p. 136; IPEA, 2010).

É importante lembrar que a gestão da dívida pública, ausente da estrutura original da STN, foi gradualmente transferida do Banco Central (BACEN) para o Tesouro. A mudança foi determinada pelo Decreto ${ }^{\circ}$ 94.443, de 12 de junho de $1987^{12}$ e, a partir daí, ocorreu uma crescente concentração das atividades de 
Ministério da Fazenda, a partir de 1 de janeiro de 1988, a competência para planejar, supervisionar, normatizar e controlar os serviços de colocação e resgate de títulos da dívida pública mobiliária federal. Parágrafo 1: Cabe à Secretaria do Tesouro Nacional propor ao Ministro da Fazenda as normas, regulamentos e demais condições a serem observadas no exercício da competência de que trata esse artigo (Decreto $n^{\circ} .94 .443$, de 12 de junho de 1987)".

Posteriormente, o Decreto $\mathrm{n}^{\circ}$. 4.643, de 24 de março de 2003 define a Secretaria do Tesouro Nacional como a área do Ministério da Fazenda responsável por "administrar as dívidas públicas mobiliária e contratual, interna e externa, de responsabilidade direta e indireta do Tesouro Nacional."

13 Para uma descrição detalhada de cada uma das funções das três coordenações-gerais alocadas na Secretaria Adjunta da Dívida Pública, veja IPEA (2010). ${ }^{14}$ Instituído em 2015 pela
portaria $S_{T N}^{\circ}{ }^{\circ} 29 / 2015$.

15 "Estratégias operacionais" referem-se ao cálculo de composição da dívida, tarefa da Subsecretaria da Dívida Pública, já que o montante de emissão é ação legalmente constrangida pela Constituição Federal, pela Lei de

Responsabilidade Fiscal, pela LDO e LOA. O Tesouro possui autonomia decisória no que diz respeito à escolha de indexadores, prazos etc., até o limite aprovado pelo Senado na peça orçamentária.

16 Indicativo disso é o relato do ex-ministro da Fazenda do primeiro governo Lula, Antônio Palocci, a respeito da nomeação de Joaquim Levy para secretário do Tesouro Nacional: "Fiquei animado com o fato de ele ser engenheiro naval e doutorado em economia pela Escola de Chicago, bom pré-requisito para guardar cofres públicos. planejamento, execução, controle e pagamento da Dívida Pública Federal no âmbito da STN. A paulatina concentração foi, portanto, um longo processo, tendo sido completado com um acordo de transição entre a STN e o BACEN datado de 7 de janeiro de 2004, quando se realizou a integral transferência da gestão da dívida externa para o Tesouro.

Esse acúmulo e complexificação de funções foi acompanhado por um incremento de sua estrutura organizacional (criação de subsecretarias) e pela formação e qualificação de quadros dotados do tipo de expertise adequado para levar a cabo tais funções, como se indicará mais adiante. Esse processo de especialização funcional e capacitação técnica foi marcado por algumas importantes etapas, dentre as quais se destacam: a criação da Coordenação-Geral de Administração da Dívida Pública (CODIP), responsável pela administração da dívida interna, e a criação da Coordenação-Geral de Assuntos Externos (COREX), então voltada para o registro contábil da dívida externa, ambas de 1988. Já nos anos 2000, em meio a um intenso processo de difusão internacional de ideias e práticas visando o aprimoramento da administração da dívida pública, a área de coordenação da dívida passou por nova reestruturação institucional, a CODIP e COREX foram reorganizadas em três novas áreas: CODIV, COGEP e CODIP, todas sob coordenação da Secretaria Adjunta da Dívida Pública ${ }^{13}$.

Atualmente a Secretaria do Tesouro Nacional está dividida em 6 Subsecretarias: de Assuntos Corporativos, de Política Fiscal, da Dívida Pública, de Relações Financeiras e Intergovernamentais, de Planejamento e Estatísticas Fiscais e de Contabilidade Pública. Adicionalmente fazem parte da estrutura da STN a Assessoria Econômica (ASSEC) e a Coordenação-Geral de Gestão de Riscos Operacionais (COGER). O próprio organograma formal da STN nos sugere haver uma clara delimitação de tarefas entre suas subsecretarias. Embora haja a necessidade de intensa troca de informações e comunicação interna entre seu corpo técnico, há também uma clara especialização funcional, na medida em que o plano de emissão e gerenciamento da dívida pública é discutido pelo Comitê de Gerenciamento da Dívida Pública Federal ${ }^{14}$, composto apenas pelo Secretário Adjunto da Dívida Pública e seus três coordenadores gerais. Outro ponto revelado pelo modo de operação desse comitê é que não há atores ou órgãos dentro do Estado com poder de veto às suas estratégias operacionais ${ }^{15}$, exceto seus superiores hierárquicos imediatos, isto é, o Secretário do Tesouro e o Ministro da Fazenda. Como sustenta nosso referencial teórico, a neutralização de atores com poder de veto sobre as políticas priorizadas e para as quais se mobilizam recursos é condição necessária para a configuração de capacidade estatal, assim como a existência de coalizões de apoio.

As informações levantadas sugerem fortemente que isso não é um impeditivo para que dirigentes da área (Secretário do Tesouro e o Ministro da Fazenda) deem diretrizes políticas às atividades de composição e gerência da dívida pública, mas a confirmação dessa questão demanda pesquisa adicional específica. Quanto ao poder de liberar e contingenciar recursos, a discricionariedade do Secretário do Tesouro é mais clara. As variações da política fiscal se dão não apenas em função da situação objetiva das finanças públicas como também da orientação política dos governos e do perfil do próprio Secretário do Tesouro ${ }^{16}$.

Todavia, o insulamento do corpo técnico da STN em relação a outros órgãos do Executivo Federal e, sobretudo, às pressões do sistema político-partidário, é acompanhado de uma estreita interação com o mercado financeiro. Na verdade, trata-se de um processo de insulamento seletivo (Silva, 2015), no qual a impermeabilidade do Tesouro ao sistema partidário se dá conjuntamente com sua inserção no mercado financeiro. Esse processo de intensa imbricação da STN com o mundo das finanças culminou com a criação da Gerência de Relacionamento Institucional do Tesouro Nacional (Gerin-STN), em 2001. 
[...] e assim, eu entreguei a ele a chave do Tesouro Nacional" (Palocci, 2007, p. 59 - grifos no original). E adiante: "Nos primeiros dois anos de governo, ele simplesmente botou o pé na porta do cofre e não permitia que ninguém ultrapassasse a linha demarcatória" (idem, p. 59-60 - grifos no original).

17 Karla de Lima Rocha foi Gerente-Adjunta de Risco da Coordenação-Geral de Planejamento Estratégico da Dívida Pública e analista da Gerência de Relacionamento Institucional.

18 Vale notar que em 2006 foi divulgado pelo Institute of International Finance (IIF) um ranking que classifica os países emergentes em suas áreas de relação com investidores (representada pela STN e Banco Central), tendo o Brasil conquistado, pela segunda vez, o primeiro lugar (STN, 2006).

\section{Considerações Finais}

Alocada na COGEP, essa gerência desempenha um importante papel na comunicação com os investidores, indicando as estratégias da política econômica, buscando consolidar e ampliar a base de investidores (Ianoni, 2017), além de conduzir reuniões periódicas com as agências de classificação de risco (STN \& Banco Mundial, 2009).

É interessante destacar que essa estreita interação tem sido defendida pelas agências internacionais, como FMI e Banco Mundial, por meio da ideia de transparência, noção que inclusive tem pautado as ações do corpo técnico da STN quando buscam aprimorar suas práticas:

A divulgação pública dos objetivos e das responsabilidades da administração da dívida pública é essencial para a conquista de credibilidade. [...] Dentre as vantagens da adoção de uma política de transparência, pode-se destacar a redução das incertezas do mercado acerca dos objetivos da política de administração da dívida pública e da consistência das decisões políticas relacionadas a esses objetivos, podendo acarretar a redução da volatilidade de mercado e do prêmio de risco exigido pelos investidores (STN \& Banco Mundial, 2009, p. 136) ${ }^{17}$.

$\mathrm{O}$ relacionamento entre a STN e o mercado financeiro se fundamenta no próprio fato de que esse detém os recursos estratégicos essenciais para a tarefa operacional da STN de garantir o financiamento estatal e gerir a dívida pública. Assim, mesmo as mais avançadas ferramentas ou, conforme a denominação trazida por nosso referencial teórico, mesmo os mais avançados recursos técnicos e operacionais e práticas de relacionamento e de transparência não são garantidores da efetiva implementação das metas e decisões dos gestores da dívida pública - isto é, dos "resultados" - pois a venda desses títulos depende de decisão soberana dos investidores de comprá-los ou não ${ }^{18}$. Isso se torna mais evidente em momentos críticos, como o que ocorreu no contexto das eleições de 2002, em que o então candidato do PT já se mostrava com grandes chances de se eleger, como o relato do secretário do Tesouro na época deixa claro:

A partir do final do primeiro semestre de 2002 o Tesouro Nacional praticamente não foi mais capaz de vender títulos públicos com vencimentos posteriores a dezembro de 2002 (Guardia, 2004).

Como é sabido, foram necessárias sinalizações de compromisso com o dito "mercado", expressas, entre outras, na famosa Carta ao Povo Brasileiro, publicada justamente no período mencionado acima, para que o Tesouro pudesse voltar a vender títulos e o financiamento estatal via emissão de títulos mobiliários voltasse a funcionar.

Cabe assinalar, por fim, que a própria viabilização do mercado financeiro de títulos públicos gerou do ponto de vista macroeconômico um resultado paradoxal. Se o objetivo que levou à criação do STN era o controle das finanças públicas (como os depoimentos aqui trazidos explicitaram), o desenvolvimento de todo o aparato institucional da STN permitiu a criação de um mercado eficiente de títulos públicos domésticos o qual, por sua vez, passou a funcionar como mecanismo de realimentação do próprio endividamento público. Isso porque a captação de recursos via emissão de títulos mobiliários e a rolagem desses títulos tornaram-se mecanismo fundamental para o funcionamento do Estado brasileiro.

O estudo sobre a STN contribui para a discussão teórica e metodológica relativa à capacidade estatal em dois pontos principais:

1) Afirma a utilidade do conceito na análise do poder: o trabalho empírico mostra que, uma vez tomada a decisão pelos governantes de priorizar determinada área em sua agenda, tal decisão é internaliza pelos 
burocratas que a assumem como sua e se mobilizam para arregimentar recursos necessários à implementação de tal prioridade. Assim, capacidade estatal abarca, de um lado, o processo de criação e expansão de recursos humanos, informacionais e financeiros para realizar tal prioridade governamental, compartilhada por políticos e pela burocracia, sendo que essa última se habilita operacionalmente e atua também politicamente para resistir às pressões de forças ou grupos contrários ao processo; de outro lado, capacidade estatal será o conceito utilizado para dar conta do estoque construído nesse processo, isto é, a capacidade instalada para continuar operando, a qual pode, dependendo de novas circunstâncias políticas, ser desmontada, como várias experiências históricas mostram.

2) $\mathrm{O}$ estudo reforça ainda a necessidade de se diferenciar analiticamente, como a literatura tem enfatizado, o conceito de capacidade estatal de resultados apresentados nas diferentes áreas de políticas públicas. No caso específico aqui analisado, a existência de déficits fiscais ou a elevação do nível do endividamento público, por exemplo, não são necessariamente indicadores de falta de capacidade estatal na área fiscal, mas resultados que podem decorrer também de fatores externos à ação estatal, como o nível da atividade econômica.

Em suma, o trabalho contribui com a literatura, reforçando que o conceito deve ser diferenciado de resultados e tomado em dupla acepção, como processo de construção de recursos e como estoque potencial de recursos já criados e postos em funcionamento. E ainda, afirma sua utilidade analítica na medida em que permite dar conta de uma forma específica de poder, aquele exercido pela burocracia.

Por fim e refletindo sobre as relações mais gerais entre Estado e economia no Brasil, pode-se observar que as mudanças qualitativas no seu papel econômico - reduzindo a função de investidor e aumentando a função de gestor da dívida pública - produziram transformações internas na estrutura institucional do Estado, no caso aqui em questão, o aumento da importância de órgãos encarregados do controle centralizado das contas públicas e da gestão de seu endividamento, o que está em sintonia com as críticas dos argumentos relativos ao encolhimento do Estado na era da globalização e com afirmação de que ocorre, na verdade, uma reestruturação e redefinição de suas dimensões e funções, e não sua diminuição.

Maria Rita Loureiro (marita.loureiro@gmail.com) possui Mestrado e Doutorado em Sociologia pela Universidade de São Paulo (1984), com pós-doutorado em Sociologia na École des Hautes Études em Sciences Sociales de Paris (1986-88) e em Ciência Política na New York University (1999-2000).

Felipe Calabrez (f.calabrez @ hotmail.com) possui mestrado em Ciência Política pela Universidade Federal do Paraná (UFPR) e doutorado em Administração Pública e Governo pela Escola de Administração de Empresas de São Paulo (EAESP-FGV).

\section{Referências}

Arrighi, G.O. (2013) Longo Século XX. Rio de Janeiro: Contraponto.

Caputo Silva, A., Carvalho, L.O., Medeiros. O.L. (orgs) (2009) Dívida pública: a experiência brasileira. Brasília: Secretaria do Tesouro Nacional: Banco Mundial.

Cingolani, L. (2013) The state of State capacity: a review of concepts, evidence and measures. Working Paper, $\mathrm{n}^{\circ} 53$ [online]. Maastricht: UNU-MERIT. Disponível em: https://cris.maastrichtuniversity.nl/ws/portalfiles/poral/978997/guid-25cb727f-2280-41f0-a1da-ecf3ac48230f-ASSET1 .0.pdf. Acesso em: 13 de dez. 2020.

Codato, A. (1997) Sistema Estatal e Política Econômica no Brasil pós-64. São Paulo: Editora Hucitec. 
Dantas, E.G., Montrose, E., Calabrez, F. \& Codato, A. (2017) Prosopografia dos ajudantes do Ministério da Fazenda: uma análise das lógicas de recrutamento, dos itinerários profissionais e do perfil social do segundo escalão. In: $41^{\circ}$ Encontro Anual da Anpocs, Caxambu.

Enriquez, E. \& Centeno, M.A. (2012) State Capacity: Utilization, Durability, and the Role of Wealth vs. History. International and Multidisciplinary Journal of Social Sciences, 1(2), pp. 130-162.

Evans, P.B., Rueschemeyer, D. \& Skocpol, T. (1985) Bringing the state back in. Cambridge: Cambridge University Press.

Evans, P. (1992) The state as problem and solution: predation, embedded autonomy and structural change. In: H. Stephan \& K. Robert (eds) Politics of Economic Adjustment. Princeton, N.J. :Princeton University Press.

Ferreira, A. (2006) Secretaria do Tesouro Nacional, 20 anos: um marco institucional na história econômica do Brasil. Brasília: Secretaria do Tesouro Nacional.

Fiori, J.L. (1998) Os moedeiros falsos. Petrópolis: Vozes.

Lopreato, F.L.C. (2013) Caminhos da Política Fiscal do Brasil. São Paulo: Editora UNESP.

Geddes, B. (1994) Politicians Dilemma. Building state capacity in Latin America. Berkeley, Los Angeles, London: University Press of California.

Gomide, A. \& Pires, R. (orgs) (2014) Capacidades Estatais: Arranjos institucionais de políticas públicas. Brasília: IPEA.

Gomide, A.; Pires, R. \& Boschi, R.R. (orgs) (2016) Capacidades estatais em países emergentes. O Brasil em perspectiva comparada. Brasilia: IPEA.

Gouvêa, G.F.P. (1994) Burocracia e elites burocráticas no Brasil. São Paulo: Paulicéia.

Grin, E. \& Abrucio F. (2018) Quando nem todas as rotas de cooperação intergovernamental levam ao mesmo caminho: arranjos federativos no Brasil para promover capacidades estatais municipais. Revista do Serviço Público, 69(4), pp. 85-122. DOI: 10.21874/rsp.v69i0.3584

Guardia, E. (2004) As Razões do Ajuste Fiscal. In: J.R. Giambiagi \& A. Urani (orgs) Reformas no Brasil: Balanço e Agenda. Rio de Janeiro: Nova Fronteira.

Haggard, S. \& Kaufman, R. (1993) O estado no início e na consolidação da reforma orientada para o mercado. In: L. Sola (org) Estado, mercado e democracia: política e economia comparadas. Rio de Janeiro: Paz e terra, pp. 391-421.

Hanson, J. \& Sigman, R. (2011) Leviathan's Latent Dimensions: Measuring state capacity for Comparative Political Research. In: American Political Science Association, Seatle. Disponível em: https://ssrn.com/ABSTRACT=899933. Acesso em: 16 de dez. 2020.

Hirsh, J. (2010) Teoria Materialista do Estado: processos de transformação do Sistema capitalista de Estado. Rio de Janeiro: Revan.

Ianoni, M. (2017) Interesses financeiros e captura do Estado no Brasil. Revista de Economia Política [online], 37(2), pp. 324-342. DOI: 10.1590/0101-31572017v37n02a04

IPEA. (2010) Estado, instituições e democracia: desenvolvimento. Livro 9, vol. 3. [online] Brasília: Instituto de Política Econômica Aplicada. Disponível em: http://repositorio.ipea.gov.br/bitstream/11058/3190/1/livro09_estadoinstituicoes_vol3.pdf. Acesso em: 13 de dez. 2020.

Kocher, M. (2010) State Capacity as a conceptual variable. [online] Yale Journal of International Affairs, 5(2). Disponível em: https://www.yalejournal.org/publications/state-capacity-as-a-conceptual-variable. Acesso em: 16 de dez. de 2020.

Krippner, G.R. (2011) Capitalizing on crises. The political origins of the Rise of Finance. Cambridge, Mass. Harvard University Press.

Lima, V.B. (2019) Arranjos institucionais e capacidades estatais para implementação de infraestrutura metroviária: nos trilhos do metrô de Salvador. Dissertação de Mestrado. São Paulo: Universidade de São Paulo. DOI: 10.11606/D.100.2019.tde-19062019-163309

Lima-Silva, F. (2019) Prioridade política e capacidade burocrática: a implementação do PAC - Urbanização de Assentamentos Precários. Tese de Doutorado. São Paulo: Fundação Getúlio Vargas. Disponível em: https://bibliotecadigital.fgv.br/dspace/handle/10438/27398. Acesso em: 13 de dez. 2020.

Lindvall, J. \& Teorell, J. (2016) State capacity as power: a conceptual framework. STANCE Working Paper Series, Vol. 2016, $\mathrm{n}^{\circ}$ 1. Lund: Lund University. Disponível em: https://ces.fas.harvard.edu/uploads/files/Event-Papers/State-Capacty-as-Power-September-2016.pdf. Acesso em: 13 de dez. 2020.

Loureiro, M.R., Abrucio, F.L. \& Rosa, C.A. (1998) Radiografia da alta burocracia federal brasileira: o caso do Ministério da Fazenda. Revista do Serviço Público, 49(4), pp. 46-82. DOI: 10.21874/rsp.v49i4.400

Marconi, N. (2017) Ajuste, poupança pública e crescimento. Revista de Conjuntura Econômica, 71(2), pp. 22-24. Disponível em: http://bibliotecadigital.fgv.br/ojs/index.php/rce/article/view/70982/68426. Acesso em: 13 de dez. 2020.

Miranda, G. \& Oliveira, V. (2018) Capacidade estatal e eficácia na política de atenção a criança e adolescente. Revista do Serviço Público, 69(1), pp. 145-180. DOI: 10.21874/rsp.v69i1.1783

Palocci, A. (2007) Sobre formigas e cigarras. Rio de Janeiro: Objetiva.

Panitch, L. (2000) The new imperial state. New left review 2, mar/apr. pp. 5-22.

Pedras, G.B.V. (2009) História da dívida pública no Brasil: de 1964 até os dias atuais. In: A. Caputo Silva, L.O. de Carvalho \& O.L. de Medeiros (orgs) Dívida Pública. A experiência brasileira. Brasília: Secretaria do Tesouro Nacional: Banco Mundial. Disponível em: https://sisweb.tesouro.gov.br/apex/f?p=2501:9::::9:P9_ID_PUBLICACAO_ANEXO:4719. Acesso em: 13 de dez. 2020.

Poulantzas, N. (1968) Pouvoir Politique et classe sociales. Paris: Maspero.

Poulantzas, N. (1977) Estado em Crise. Rio de Janeiro: Graal. 
Rocha, K.L. (2009) Estrutura Institucional e Eventos Recentes na História da Administração da Dívida Pública Federal. In: A. Caputo Silva, L.O. de Carvalho \& O.L. de Medeiros (orgs) Dívida Pública. A experiência brasileira. Brasília: Secretaria do Tesouro Nacional: Banco Mundial.

Schneider, B.R. \& Doner, R.F. (2000) The new institutional economics, Business associations, and Development. Brazilian Journal of Political Economy, 20(3). Disponível em: https://centrodeeconomiapolitica.org.br/rep/index.php/journal/article/view/1004. Acesso em: 13 de dez. 2020.

STN. (2006) Secretaria do Tesouro Nacional, 20 anos: um marco institucional na história econômica do Brasil. Brasília: Secretaria do Tesouro Nacional.

Silva, C., Carvalho, L.O. de \& Medeiros, O.L. de (orgs) (2009) Dívida Pública. A experiência brasileira. Brasília: Secretaria do Tesouro Nacional: Banco Mundial.

Silva, A., Meneses, D.B. \& Medeiros, O.L. (2009) Conceitos e estatísticas da dívida pública. In: Silva, A. Meneses, D.B. \& Medeiros, O.L. (orgs.) Divida Pública. A experiência brasileira. Brasília: Secretaria do Tesouro Nacional: Banco Mundial.

Sikkink, K. (1991) Ideas and Institutions: Developmentalism in Brazil and Argentina. Ithaca, New York: Cornell University Press.

Silva, L. (2015) A burocracia de médio escalão da Secretaria da Receita Federal do Brasil: insulamento seletivo e construção de capacidades burocráticas. In: P. Cavalcante \& G.S. Lotta (orgs) Burocracia de médio escalão: perfil, trajetória e atuação. Brasília: ENAP.

Skocpol, T. (1979). States and social revolutions: A Comparative Analysis of France, Russia and China. New York and Cambridge: Cambridge University Press.

Skocpol, T. (1985) Bringing the State Back in: Strategies of Analysis in Current Research In. P. Evans, D. Rueschemeyer \& T. Skocpol (orgs) Bringing the State Back In. Cambridge University Press

Soifer, H.D. (2012). Measuring State Capacity in Contemporary Latin America. Revista de Ciência Política, 32(3), pp. 585-98. DOI: $10.4067 /$ S0718-090X2012000300004

Souza C. (2017) Modernização do Estado e construção de capacidade burocrática para a implementação de políticas federalizadas. Revista Administração Pública, 51(1), pp. 27-45. DOI: 10.1590/0034-7612150933

Wheller, G. (2004) Sound Practice in government debt management. Washington, DC: World Bank. Disponível em: http://hdl.handle.net/10986/15017. Acesso em: 13 de dez. 2020.

Wu, X., Ramesh, M. \& Howlett, M. (2015) Policy capacity: A conceptual framework for understanding policy competences and capabilities. Policy and Society, 34(s/n), p. 165-171. DOI: 10.1016/j.polsoc.2015.09.001

State capacity and public debt in Brazil: The case of the National Treasury

ABSTRACT Introduction: The literature on state capacity has grown in recent decades, but several theoretical and methodological problems have been pointed out in studies on the subject. Even guided by policymakers' concerns, the concept can also have analytical utility. Thus, this article resumes and redefines it to explain processes of transformation within the Brazilian State. Materials and Methods: We conducted here a case study of the process of capacity building in the fiscal area by the State in Brazil. The empirical object of analysis is the National Treasury Secretariat of the Ministry of Finance, an agency created in the context of the State's fiscal crisis, in charge of public debt management and unified control of the federal government's budget execution. The empirical material of the analysis is composed of qualitative and quantitative elements. Results: In dialogue with the literature and distinguishing the capacity for results, the analysis shows that despite the temporal variations presented by the fiscal area (greater or lesser deficit, greater or lesser level of indebtedness), which depend on contingent economic factors, it is possible to verify the existence of state capacity in public debt management in Brazil, resulting from the deliberate action of the economic bureaucracy, carried out over several decades and which remains as a feature today constituting the Brazilian State. Discussion: The preliminary findings seek to contribute to the literature on state capacities and affirm their analytical usefulness insofar as it allows to account for a specific form of power, that exercised by bureaucracy.

KEYWORDS: state capacity; public debt management; National Treasury Secretariat; economic bureaucracy; Brazilian State.

This is an Open Access article distributed under the terms of the Creative Commons Attribution Non-Commercial License which permits unrestricted non-commercial use, distribution, and reproduction in any medium provided the original work is properly cited.

A produção desse manuscrito foi viabilizada através do patrocínio fornecido pelo Centro Universitário Internacional Uninter à Revista de Sociologia e Política. 